\title{
VISIÓN INTEGRADORA DE INFORMACIÓN FINANCIERA, SOCIAL Y ÉTICA
}

\section{INTEGRATED VIEW OF FINANCIAL, SOCIAL AND ETHICAL INFORMATION}

\section{Elsa E. Choy Zevallos $1^{1}$}

Profesor Asociado de la Facultad de Ciencias Contables, UNMSM

[Recepción: Abril de 2009 / Conformidad: Mayo de 2009]

\section{RESUMEN}

En la actualidad, la información contable tradicional, que expresa los resultados económicos y financieros de una entidad, no satisface las necesidades de conocimiento sobre el desempeño organizativo global que tienen los accionistas, clientes, inversionistas, el gobierno, las organizaciones de la sociedad civil y otras partes interesadas de la empresa.

La necesidad de contar con información que abarque una visión integradora, es decir, las dimensiones sociales, económicas, políticas, ambientales, educativas; es un aspecto de vital importancia para las empresas y esta función le corresponde al contador, quien es el encargado de procesar información económica financiera, complementada con aspectos sociales y medioambientales.

El propósito de este tema es presentar un nuevo enfoque de información financiera, donde refleje la influencia del medioambiente en el desarrollo de las actividades, con responsabilidad social de la unidad económica. Asimismo, destacar la participación fundamental de la profesión contable y su rol ético en esta actividad.

Palabras clave: Información económica-financiera, balance social, indicadores de responsabilidad social e impacto medioambiental, valores éticos, contador público.

\begin{abstract}
At present, the traditional accounting information, which expresses the economic and financial results of an entity, does not meet the needs of knowledge about the overall organizational performance that have shareholders, customers, investors, government, civil society organizations and other stakeholders of the company The need for information that includes a vision, in the social, economic, political, environmental, educational and its a vitally important aspect to this business and it is the accountant, which is responsible for processing economic and financial information, together with social and environmental aspects. The purpose of this subject is to present a new approach to financial reporting, which reflects the influence of environment on the development of activities, with social responsibility of the economic unit. Also highlight the critical involvement of the profession and the role of ethics in this activity.
\end{abstract}

Keywords: Economic-financial information, social balance, indicators of social responsibility and environmental impact, ethics, public accountant.

1 Contador Público Colegiado, UNMSM; y Magíster en Contabilidad- UNMSM. 


\section{INTRODUCCIÓN}

La contabilidad ha tenido una concepción utilitarista y mecanicista del proceso de elaboración de la información contable. Este enfoque ha supuesto una visión parcial del entorno en el que opera, donde el marco, aún predominante, es el de una economía de mercado, con propiedad privada de los medios de producción, decisiones económicas dispersas y ánimo de lucro, que ha generado distintos desvalores.

Actualmente, la contabilidad se define dentro de un marco económico determinado y dicho marco está evolucionando con cierta rapidez, en este sentido la función y el rol ético del contador público es fundamental para la preparación de la información contable, ya que debe insertar estos cambios en la información financiera, reflejando un enfoque social. Asimismo, la aplicación de prácticas contables deben perseguir la creación de una imagen de la realidad, transformando los flujos físicos en cifras, sus diferencias cualitativas y cuantitativas en valores financieros, es decir convertir cualidades en cantidades.

El objetivo del presente tema es señalar un nuevo enfoque de información financiera donde refleje la influencia del medioambiente en el desarrollo de las actividades, así como expresar la necesidad de integrar a la misión y visión de la empresa las prácticas en responsabilidad social bajo un nuevo entorno económico.

El tema consta de cuatro puntos, problemática, bases teóricas relacionadas con información contable y responsabilidad social, balance social e indicadores, finalmente presenta conclusiones, recomendaciones y blibliografía consultada.

\section{PROBLEMÁTICA}

Si tenemos en cuenta que el enfoque tradicional de la contabilidad ha sido "procesar e informar sobre la situación económica y financiera de una entidad", este enfoque, sin embargo, ha supuesto una visión parcial del entorno en el que opera, ya que la contabilidad también tiene un enfoque social y las prácticas contables persiguen la creación de una imagen de la realidad a la que se aplican; transformando los flujos físicos en cifras, sus diferencias cualitativas y cuantitativas en valores financieros, es decir, recoge aspectos cualitativos y las convierte en cantidades.

La responsabilidad social que se le asigna a la nueva economía social de mercado supone una alteración de los contenidos que, en la información financiera, ha de suministrar la unidad económica, debiendo estar entre ellos la situación medioambiental, lo que supone asumir un respeto hacia el medio ambiente en sus operaciones, ya que cada vez son más los sectores de la sociedad que dan mayor importancia a los problemas medioambientales y esta evolución implica que los usuarios de la información contable, como parte importante del entorno donde se desarrolla la actividad económica, impulsan los cambios a efectuar en la presentación de dicha información.

Como consecuencia de las nuevas estrategias, obliga a las empresas a reformular los objetivos tradicionales como son: la obtención de beneficio y la permanencia de la empresa, ahora deberán incorporar otros como son la mejora de la calidad de vida y del medioambiente.

Frente a esta realidad problemática, es posible plantear las siguientes interrogantes:

¿Cuál es la participación de la profesión contable y su rol ético en relación a la información sobre responsabilidad social en los estados contables de las empresas?

¿Quéindicadores sobre responsabilidad social y medioambiente deben considerarse para alcanzar una información contable integral? 


\section{ANTECEDENTES TEÓRICOS}

- Gerardina González Mallorquín señala que "La gran responsabilidad de las empresas, es mantenerse activas, rentables, compitiendo, produciendo en el mercado. Cuando una empresa es rentable no solo produce un retorno para sus dueños o accionistas, sino que también genera consecuencias sociales favorables tales como nuevas oportunidades de empleo a través de su expansión e inversión, provisión de bienes y servicios valiosos para la sociedad, etc.. Bajo esta perspectiva, la responsabilidad de la empresa es mantenerse como empresa.

- Paulo Itacarambi, director ejecutivo de Ethos, asegura que "se pueden hacer negocios que sean buenos para la empresa y para la sociedad y contribuir al desarrollo colectivo". Asimismo, "Tenemos que mostrar que las empresas que hacen RSE también ganan dinero".

- Peter Utting, jefe de Proyecto del Instituto de Investigación de las Naciones Unidas para el Desarrollo Social, en su informe sobre el Pacto Mundial, dice: "Los críticos de la iniciativa temen que pueda contribuir más a mejorar la imagen de las grandes empresas que a ayudar al medio ambiente y a los necesitados. Las empresas pueden elegir libremente cuáles de los principios del Pacto van a abordar, y no se supervisa su cumplimiento. Centrarse en las buenas prácticas desvía la atención de las prácticas indebidas, el 'lavado verde' o 'greenwash' (mediante el cual las empresas tapan sus prácticas antiecológicas) y factores estructurales y de otra índole que alientan la irresponsabilidad empresarial o 'dejar las cosas como están."

\section{BASES LEGALES}

- La Constitución Política del Perú

- Ley 28611, Ley General del Ambiente (LGA)

- Ley 28245, Ley del Sistema Nacional de Gestión Ambiental (LSNGA)

- Ley del Consejo Nacional del Ambiente (Ley 26410)

- Normas ISO 14000 y 14063

- ISO 14031, Norma para el Desempeño Ambiental

- La norma ISO 26000 Principios sobre Responsabilidad Social

- La norma SA 8000 Normas Laborales y Gestión sobre RS

\section{LA INFORMACIÓN FINANCIERA Y SUS LIMITACIONES}

La información financiera no refleja:

- El impacto de las actividades de los diferentes sectores empresariales sobre el medio ambiente.

- Gestión energética, excesos o ahorros de energía.

- Gestión de materias primas, desperdicios o ahorros, selección y transporte, y exceso o ahorro de agua.

- Despilfarro, reciclaje, reutilización, transporte y desecho.

- Reducción de ruidos dentro y fuera de la localización.

- Selección de nuevos procesos, o cambios sustanciales a los procesos en operación.

- Desempeño ambiental y procedimientos para tratar con contratistas, subcontratistas y proveedores.

- Prevención y limitación de accidentes ambientales.

- Definición de procedimientos de prevención de accidentes ambientales. 


\section{RESPONSABILIDAD SOCIAL}

La responsabilidad social es de naturaleza ética y su conocimiento se estructura en un modelo teleológico: "todo lo que se hace, se hace con algún fin"; que incluye valores, objetivos, metodologías e instrumentos de información y control.

Los especialistas en este tema han desarrollado diversas teorías, sin embargo, todos coinciden que responsabilidad social "Es una filosofía que tiene como pilares fundamentales, valores éticos y morales y cuya principal incidencia se manifiestan en nuestros actos y de qué manera estos pueden afectar o dañar a otra persona o a un determinado entorno social”.

\section{RESPONSABILIDAD SOCIAL EMPRESARIAL}

La responsabilidad social está directamente relacionada con la empresa, pues le ayuda a tomar conciencia de su rol, reconociéndose como agente de cambio para mejorar la calidad de vida y la competitividad de su entorno.

Diversos son los conceptos y enfoques sobre responsabilidad social empresarial (RSE), que presentan los autores, tales como:

El economista y sociólogo Baltazar Caravedo Molinari, presidente de SASE (Servicios para el Desarrollo), en su artículo "Responsabilidad Social una forma de gerenciar", señala lo siguiente:

"Hemos señalado en anteriores publicaciones que la época que vivimos - caracterizada por la existencia de un mundo globalizado, por los cambios en la comunicación y la velocidad en la generación de nuevos conocimientos- está produciendo un nuevo tipo de consumidor. A éste ya no sólo le interesan el precio y la calidad misma del bien o producto que compra, ahora también le interesa quién lo produce y qué tan responsablemente se maneja con su entorno."

Paladino y otros señalan:

"Se conoce de la RES muchas cosas, que significa actuar responsablemente en todos los niveles de la empresa y que debe abarcar y atravesar a todas las personas, politicas y acciones empresarias. Sin embargo, todavía lo que las empresas comunican de su RES está fuertemente vinculada a sus acciones por la comunidad. Falta un avance en el reporte integral de la RES; probablemente esto se deba a que también falta integrar la RES a toda la empresa. Recién cuando se haya podido integrar la RES a toda la organización, se podrá reportar integramente".

En síntesis, RSE es una forma ética de gestión que implica la inclusión de las expectativas de todos los grupos de interés (accionistas/ inversionistas, colaboradores y sus familias, comunidad, clientes, proveedores, medioambiente y Gobierno) alrededor de la empresa, para lograr el desarrollo sostenible.

\section{CONTABILIDAD Y MEDIO AMBIENTE}

El autor Enrique Rafael Blanco Richard, refiriéndose al tema, señala que ante el problema histórico de la relación entre economía y medio ambiente, los representantes de un nuevo análisis económico intentan resucitar

2 PALADINO, M.; MILBERG, A.; SÁNCHEZ IRIONDO, F. (2006). Emprendedores sociales \& empresarios responsables. Buenos Aires: Ed. Temas, p. 49. 
EMPRESA Y RESPONSABILIDAD SOCIAL

\begin{tabular}{|c|c|c|c|c|}
\hline & PRODUCCIÓN & $\begin{array}{l}\text { PRODUCTIVIDAD } \\
\text { LABORAL }\end{array}$ & VENTAS & UTILIDADES \\
\hline \multirow[t]{2}{*}{$\begin{array}{l}\text { OBJETIVO } \\
\text { ¿Qué buscamos? }\end{array}$} & Productos de calidad & $\begin{array}{l}\text { Aumento en la } \\
\text { productividad del trabajo }\end{array}$ & Clientes fieles & Mayores que el resto \\
\hline & Productos de calidad & $\begin{array}{l}\text { Aumento en la } \\
\text { productividad del trabajo }\end{array}$ & Clientes fieles & Mayores que el resto \\
\hline $\begin{array}{l}\text { Situación } \\
\text { ¿Cómo estamos? }\end{array}$ & $\begin{array}{l}\text { En tecnología } \\
\text { En contaminación } \\
\text { En seguridad } \\
\text { En calidad } \\
\text { Volumen }\end{array}$ & $\begin{array}{l}\text { En organización } \\
\text { En capacitación } \\
\text { En motivación } \\
\text { En nivel de satisfacción } \\
\text { Índice de productividad }\end{array}$ & $\begin{array}{l}\text { Monto total } \\
\text { Imagen de producto } \\
\text { Imagen de empresa } \\
\text { Nivel de fidelidad del } \\
\text { cliente } \\
\text { Inversión social }\end{array}$ & $\begin{array}{l}\text { Monto } \\
\text { Registro histórico } \\
\text { Por rama } \\
\text { General }\end{array}$ \\
\hline $\begin{array}{l}\text { Estrategia } \\
\text { ¿Qué hacemos? }\end{array}$ & $\begin{array}{l}\text { Cambio tecnológico } \\
\text { Disminución de la } \\
\text { contaminación } \\
\text { Incremento de la } \\
\text { seguridad } \\
\text { Mejora de la calidad }\end{array}$ & $\begin{array}{l}\text { Mejora organizacional } \\
\text { Ampliación de la } \\
\text { capacitación } \\
\text { Incremento de la } \\
\text { motivación } \\
\text { Potenciar la satisfacción } \\
\text { Incrementar el índice }\end{array}$ & $\begin{array}{l}\text { Incrementar el monto total } \\
\text { Mejorar la imagen de } \\
\text { producto } \\
\text { Mejorar la imagen de la } \\
\text { empresa } \\
\text { Incrementar la fidelidad del } \\
\text { cliente } \\
\text { Mejorar la inversión social }\end{array}$ & Incrementar \\
\hline $\begin{array}{l}\text { Política } \\
\text { ¿Cómo lo } \\
\text { hacemos? }\end{array}$ & $\begin{array}{l}\text { Contar con proveedores } \\
\text { verdes } \\
\text { Manejo de residuos } \\
\text { Cambio de equipos } \\
\text { Reglas de seguridad }\end{array}$ & $\begin{array}{l}\text { Talleres con gerentes } \\
\text { Talleres con empleados } \\
\text { Mejora salarial } \\
\text { Oportunidades } \\
\text { extralaborales }\end{array}$ & $\begin{array}{l}\text { Talleres con gerentes } \\
\text { Difusión realizada por } \\
\text { trabajadores } \\
\text { Difusión por clientes } \\
\text { Publicidad } \\
\text { Invertir en la comunidad }\end{array}$ & \\
\hline $\begin{array}{l}\text { Imagen } \\
\text { ¿Qué se percibe? }\end{array}$ & Calidad del producto & $\begin{array}{l}\text { Satisfacción de los } \\
\text { trabajadores }\end{array}$ & Calidad de la empresa & \\
\hline $\begin{array}{l}\text { Impacto } \\
\text { ¿Qué resultado } \\
\text { tiene? }\end{array}$ & $\begin{array}{l}\text { Velocidad de producción } \\
\text { Nivel interno de } \\
\text { contaminación } \\
\text { Nivel externo de } \\
\text { contaminación } \\
\text { Accidentes de trabajo } \\
\text { Calidad del producto }\end{array}$ & $\begin{array}{l}\text { Mayores destrezas } \\
\text { Disminución de la } \\
\text { rotación } \\
\text { Mayor participación } \\
\text { en actividades de la } \\
\text { empresa } \\
\text { Beneficios de los } \\
\text { trabajadores } \\
\text { Índice de productividad }\end{array}$ & $\begin{array}{l}\text { Participación en el } \\
\text { mercado } \\
\text { Percepción del producto } \\
\text { Percepción de la empresa } \\
\text { Mejoras sociales }\end{array}$ & \\
\hline $\begin{array}{l}\text { Medición } \\
\text { ¿Cómo lo } \\
\text { medimos? }\end{array}$ & Registro interno & $\begin{array}{l}\text { Registro interno } \\
\text { Focus group } \\
\text { Encuestas }\end{array}$ & $\begin{array}{l}\text { Registro interno } \\
\text { Encuestas } \\
\text { Focus group }\end{array}$ & Balance \\
\hline
\end{tabular}

en sus trabajos la íntima relación que guardaban ambas en el primer modelo económico elaborado por los fisiócratas, en especial por Francois Quesnay en su Tableau economique.

A su vez la contabilidad como disciplina académica y herramienta de trabajo económico también está inmersa en el mismo intento de reflejar en sus informaciones financieras la influencia del medio ambiente en el desarrollo de las actividades económicas que se aplican; transformando los flujos físicos en cifras, sus diferencias cualitativas y cuantitativas en valores financieros, etc., es decir, convierte cualidades en cantidades.

\section{BALANCE SOCIAL}

Es sabido que los balances contables tienen relación con el proceso de difusión pública 
de los resultados económicos, sin embargo, la información financiera ya no basta por sí sola para satisfacer las necesidades de conocimiento sobre el desempeño organizativo global que tienen los accionistas y otras partes interesadas de la empresa.

Los clientes, los inversores, el gobierno, las organizaciones de la sociedad civil, los socios comerciales y la sociedad en general están solicitando a las empresas mayor información sobre su desempeño social.

Según el Instituto ETHOS, "el Balance Social puede ser definido como el reporte anual producido voluntariamente por la empresa luego de una auditoría interna, para identificar su grado de responsabilidad social. La auditoría interna busca entender la gestión del negocio y evaluarla según criterios ambientales y socioeconómicos, en los diversos niveles: políticas de buen gobierno corporativa, valores, visión de futuro y desafíos propuestos".

El balance social incluye datos cuantitativos y cualitativos que pueden orientar la planificación de las actividades de la empresa para el año siguiente, además de mostrar el desarrollo de las actividades del año anterior.

\section{MODELOS DE BALANCES SOCIALES}

\section{Modelo IBASE}

Lanzado en 1997 por el Ibase, se inspira en el formato de los balances financieros.

Expone, de manera detallada, los números asociados a responsabilidad social de la organización. En forma de planilla, reúne informaciones sobre la ficha de pagos, los gastos con cargas sociales de funcionarios, la participación en los lucros. También detalla los gastos en el control ambiental y las inver- siones sociales externas de las diversas áreas: educación, cultura, salud, etc.

\section{Modelo ETHOS}

Basado en el reporte detallado de los principios y las acciones de la organización, incorpora la planilla propuesta por el Ibase y sugiere un análisis mayor del contexto en la toma de decisiones, de los problemas encontrados y de los resultados obtenidos. El Instituto ETHOS establece que los balances sociales adquieren credibilidad si se verifican los siguientes principios: relevancia, veracidad, claridad, nivel de comparación, regularidad, nivel de verificación.

\section{Modelo GRI}

Global Reporting Initiative (GRI). Su objetivo es adoptar un modelo de patrón internacional para los balances sociales. La misión de la GRI es que los balances sociales se vuelvan modelos tan difundidos como los balances financieros corporativos. Por lo tanto, ella se empeña en producir y diseminar un modelo que pueda ser aplicado globalmente.

\section{INDICADORES}

\section{Indicadores de responsabilidad social}

En términos de negocios, la búsqueda de la sustentabilidad puede ser resumida como una estrategia amplia de gerenciamiento de riesgos. La capacidad de prever y contener el riesgo, transformando el mismo en oportunidad, es lo que caracteriza al emprendedor socialmente responsable. Las nuevas transformaciones presentes en el mercado proporcionan desafíos que constituyen condiciones a ser tomadas en cuenta a la hora de incorporar nuevas oportunidades en los negocios y 
ellas estimulan la incorporación de criterios de sustentabilidad.

En su gestión de responsabilidad social, la empresa establecerá sus criterios de sostenibilidad en base a indicadores cualitativos y cuantitativos, de desempeño ético social y ambiental con sus partes interesadas.

En la actualidad, muchas empresas utilizan los indicadores para adaptarse al nuevo paradigma empresarial. Es importante recalcar que estos indicadores reflejan diferentes niveles de responsabilidad social. Evolucionar de un nivel a otro exige compromiso, planeamiento e inversiones.

\section{Indicadores ETHOS de Responsabilidad Social Empresarial}

Constituyen una herramienta que las organizaciones pueden utilizar para autoevaluar sus prácticas socialmente responsables mediante una lista que debe ser verificada por ella misma.

\section{Indicadores de desempeño medio am- biental:}

- Indicadores de desempeño operacional Evalúan los materiales, la energía, el consumo de agua, los desechos y las emisiones en cantidades totales y en relación con los volúmenes de producción.

- Indicadores de desempeño de gestión Miden los esfuerzos de protección ambiental llevados a cabo por el ente.

- Indicadores de la condición ambiental Miden la calidad del medio ambiente

\section{CONCLUSIONES}

1. Pocas son las universidades de nuestro país que incorporan en la formación profesional aspectos estratégicos gerenciales para la transparencia, la calidad y la res- ponsabilidad social como herramientas para ser competitivas.

2. El valor de la información es primordial en la redefinición del paradigma ético en las empresas; por eso, el rol del contador público juega un papel trascendental como encargado de la existencia de sistemas de información que capten datos cualitativos $y$ cuantitativos asequibles a los destinatarios de su acción, a la vez que confiables y verificables para contribuir a su credibilidad.

3. La información social es un elemento importante en la cadena de valor de toda organización $y$, de ser adecuadamente revelada, prestigia socialmente a las empresas. La importancia de indicadores sobre responsabilidad social y ambiental, como complemento a los estados financieros, deben invitar a la adopción de estas prácticas

4. La responsabilidad social empresarial alude al modo en que la empresa se relaciona e impacta sobre la sociedad a través de sus prácticas, y a la influencia que la sociedad y los agentes sociales tienen sobre la empresa.

\section{REFERENCIAS BIBLIOGRÁFICAS}

1. Araujo Ensuncho, J. A. (1999). Contabilidad Social. 2. a edición. Argentina: Tiempos Gráficos.

3. Carmona, H. (2004). La contabilidad de los costos ambientales. Argentina.

4. Cea Briceño, Á. (2004). La adaptación del cuadro de mando integral a la gestión universitaria. Santiago de Chile.

5. Cooper, James (1993). Estrategias de enseñanza universitaria, México: Edit. Limusa. 
6. Vidal Martínez, I. (2002). Reflexiones sobre responsabilidad social como estrategia empresarial. Madrid: Grupo CIES.

7. Villar Borrero, E. (2004). Proyección social de la empresa. Reflexiones interrogantes". Colombia.
8. Graham, A. y Morse, R.J. http://www.usnews.com, 2000. (Visitado el 12-04-09).

9. Martínez, Eduardo. (1999). UNESCO: www.unesco.org.uy/ La evaluación de la educación superior. (Visitado el 1804-09). 